\title{
QUEM ESCONDEU O RITMO OCULTO? UM ESTUDO COMPARADO ENTRE OS RITMOS ESCOLARES NO BRASIL E NA FRANÇA
}

\author{
Rosa Maria Bortolotti de CAMARGO ${ }^{i}$ \\ Rosane Carneiro SARTURIii
}

\begin{abstract}
RESUMO
Neste estudo, considerou-se o Ritmo Escolar como o componente do currículo escolar responsável pela estruturação, organização do tempo escolar e extracurricular. O objetivo foi analisar como os Ritmos Escolares, no Brasil e na França, se manifestam nos cotidianos escolares, considerando o exemplo de duas escolas públicas de periferia, uma em cada país. O tempo passado na escola foi estudado a partir de uma visão crítica do currículo, na perspectiva do formal, real e oculto. A investigação comparada constatou que no Brasil e na França o Ritmo Escolar estabelece uma relação de causalidade com o sucesso, fracasso escolar e social, por meio da ideia de que (re) organização, criação, melhoramento e qualificação dos diferentes tempos e espaços escolares são fatores importantes para diminuir as desigualdades escolares e, consequentemente, as sociais, sobretudo, das crianças oriundas das camadas mais populares.
\end{abstract}

PALAVRAS-CHAVE: Ritmo escolar; Ritmo formal; Ritmo oculto; Cotidianos escolares.

\section{WHO HID THE IMPLIED ROUTINE? A COMPARATIVE STUDY BETWEEN SCHOOL ROUTINE IN BRAZIL AND IN FRANCE}

\begin{abstract}
School Rhythm was considered as a component of the school curriculum responsible for structuring, organizing school and extracurricular time. It aimed to analyze how School Rhythms, in Brazil and France, are manifested in school daily life, considering the example of two public schools in the periphery, one in each country. The time spent at school was studied from a critical view of the curriculum, from the perspective of the formal, real and hidden. The comparative investigation found that in Brazil and France the School Rhythm establishes a causal relationship with success, school and social failure, through the idea that the (re) organization, creation, improvement and qualification of different school times and spaces are important factors to reduce school inequalities and, consequently, social inequalities, especially for children who come from the most popular classes.
\end{abstract}

KEYWORDS: School routine; Formal routine; Implied routine; Daily school life.

\footnotetext{
${ }^{\mathrm{i}}$ Doutoranda da Universidade de Cergy-Pontoise, Mestre em Educação e Pedagoga pela Universidade Federal de Santa Maria. E-mail: bortolottidecamargorosamaria@outlook.fr.

ii Doutorado em Educação pela Universidade Federal do Rio Grande do Sul. Professora Associada da Universidade Federal de Santa Maria no Departamento de Administração Escolar. E-mail: rcsarturi@gmail.com.
} 


\title{
¿QUIÉN ESCONDIO EL RITMO OCULTO? UN ESTUDIO COMPARATIVO ENTRE LOS RITMOS ESCOLARES EN BRASIL Y EN FRANCIA
}

\begin{abstract}
RESUMEN
El Ritmo Escolar fue considerado como un componente del curriculo escolar responsable de estructurar, organizar la escuela y el tiempo extracurricular. Su objetivo era analizar cómo los ritmos escolares, en Brasil y Francia, se manifiestan en la vida diaria de la escuela, considerando el ejemplo de dos escuelas públicas en la periferia, una en cada país. El tiempo pasado en la escuela se estudió desde una visión crítica del curriculum, desde la perspectiva de lo formal, real y oculto. La investigación comparativa encontró que en Brasil y Francia el Ritmo Escolar establece una relación causal con el éxito, el fracaso escolar y social, a través de la idea de que la (re) organización, creación, mejora y calificación de diferentes tiempos y espacios escolares son factores importantes para reducir las desigualdades escolares y, en consecuencia, las desigualdades sociales, especialmente para los niños que provienen de las clases más populares.
\end{abstract}

PALABRAS CLAVE: Ritmo escolar; Ritmo formal; Ritmo oculto; Cotidianos escolares.

\section{INTRODUÇÃO}

“Quem escondeu o Ritmo Oculto ${ }^{1}$ ?" foi uma pesquisa de metodologia comparada, entre Brasil e França, que teve como tema os Ritmos Escolares ou o tempo que as crianças dos anos iniciais da educação básica pública passam na escola nos dois países. A construção da pesquisa se iniciou com uma reflexão teórica sobre como se problematizaria este tema, considerando que ambos os países são relativamente distintos. Utilizando as recomendações de Vigour (1995 p. 6, tradução nossa) de que "[...] para poder julgar a pertinência de uma ou tal comparação, é necessário de perguntar '[...] comparáveis com respeito às quais propriedades ou características e incomparáveis (por exemplo, o excesso de diferenças) [...]”, o primeiro passo dado na investigação foi tentar delimitar os debates, os termos, as palavras-chave, de forma a inscrever os dois países em uma mesma linha discursiva.

Brasil e França possuem interesses que se assemelham no debate principal que versa sobre a ideia de que é possível combater as desigualdades escolares, seja no campo da aprendizagem, seja no das desigualdades sociais, manifestadas nas escolas localizadas em bairros mais pobres, por meio de melhoramento, (re) planejamento, criação, qualificação, aumento ou (re) organização do tempo escolar.

Algumas estratégias previstas para esse combate seriam: aumentar o número de horas de escola por dia; qualificar as atividades que são propostas na rotina diária da escola; adicionar princípios políticos, sociais e culturais às atividades extraescolares, bem como às atividades 
formais da escola e reequilibrar a divisão das diferentes atividades escolares, tratando de priorizar e respeitar os ritmos biológicos das crianças e adolescentes.

A partir de uma perspectiva crítica do currículo (MOREIRA; SILVA, 1995) e tratando de analisar tais concepções sobre os diferentes tempos de escola, foi necessário universalizar os termos da investigação, portanto, se propôs a expressão Ritmo Escolar buscando analisá-la nas dimensões formal e oculto.

\section{METODOLOGIA}

O objetivo consistiu em analisar como os Ritmos Escolares, no Brasil e na França, se manifestam nos cotidianos, considerando o exemplo de duas escolas públicas de periferia, uma em cada país, nas quais foram realizadas observações participantes e entrevistas semiestruturadas durante o ano de 2017. Uma escola está localizada na cidade de Santa Maria, no Estado do Rio Grande do Sul, Brasil e a outra, na cidade de Rennes, na região da Bretanha, na França.

$\mathrm{Na}$ escola brasileira (EBr) observou-se uma turma de $5^{\circ}$ ano (Turma Verde). Na escola da França (EFr), uma turma de $3^{\circ}$ ano (Turma Vermelha). Também foram observados os tempos de atividades extracurriculares, que na França são chamados de Temps d'Activié Périscolaire (TAP) e no Brasil, Novo Mais Educação (NME).

Neste artigo nos concentramos, sobretudo, na descrição das observações feitas $^{2}$ e apresentamos alguns fragmentos das entrevistas realizadas com os seguintes atores: no Brasil, com a professora regente da Turma Verde, um coordenador e um mediador do Programa NME. $\mathrm{Na}$ França, com a professora regente da Turma Vermelha, e a coordenadora do TAP.

\section{RITMO FORMAL E RITMO REAL}

As proposições conceituais da teoria curricular montam uma linha histórica explicando que primeiramente o currículo representou um estudo técnico e metódico da forma como deveria funcionar a escola. Depois disso, voltou-se para um estudo dos discursos e ideologias implícitas que permeiam as instituições escolares (MOREIRA; SILVA, 1995). Sendo assim, as organizações escolares são inicialmente analisadas em dois eixos básicos: formal e real. Mais adiante, outras formas de interpretar a organização escolar, manifestamente os estudos críticos do currículo, para além da organização formal e real surgiram com a análise da existência de 
uma organização escolar oculta que permeia as demais organizações. A presente pesquisa está fundamentada nessa interpretação curricular, ou seja, de que há um currículo formal, real e oculto (LOPES; MACEDO, 2011).

No que tange ao tempo que se passa na escola, o currículo formal se materializa e diz respeito, somente, à organização de horários determinados para acontecer cada atividade através de uma recomendação legal. E, é por isso que, segundo Palamidessi (2002, p. 115), “[...] todo currículo tem um quadro como figura básica. [...]" que é respaldado por alguma lei ou orientação a qual legisla sobre o tempo de funcionamento da escola. Essa organização legal do tempo de escola é entendida neste estudo como Ritmo Formal.

No âmbito da teoria curricular, constata-se que as propostas legais são sempre adaptadas dentro dos espaços escolares, seja por conta das singularidades do contexto social em que a escola está inserida, seja pela forma como a gestão compreende o sistema de ensino ou a particularidade do público que recebe. Assim, desenvolveu-se um conceito sobre esse processo de adaptação curricular à norma legal chamado de currículo real.

Para Perrenoud (2013) o currículo real não é somente como o professor gera o funcionamento de sua aula tomando como base as suas inclinações culturais e sociais, respaldado nas orientações legais, mas, também, as ações que exercem os alunos durante o desenvolvimento da aula. O currículo real não deixa de ser uma adaptação à norma legal que materializa, de certa maneira, um espaço de negociação entre professores e alunos sobre como irá se dar o funcionamento prático das aulas. Assim, pode-se afirmar que o currículo real é a primeira manifestação de um campo de batalha entre todos os atores escolares.

Nesta pesquisa sobre o tempo de escola, o Ritmo Escolar Real seria, portanto, a forma como a escola se organiza temporalmente, considerando as disposições legais, os limites e possibilidades locais. Um exemplo clássico do Ritmo Real manifestado na EBr, por exemplo, foi o do horário de entrada às $7 \mathrm{~h} 40$, em dias de inverno, sendo flexibilizado até $8 \mathrm{~h} 30$ em dias de chuva. Pois, a direção escolar entendia que os alunos tinham mais dificuldade para $\forall i$ à escola e até mesmo se levantar de manhã.

Todo país possui uma legislação nacional que considera os aspectos sobre a quantidade de dias e horários escolares. A partir de cada realidade social e econômica, existem formas de funcionamento escolar em uma perspectiva quantitativa. A organização de horários pode ter detalhamentos mais ou menos exigentes: modelos de horários a serem aplicados em todo o país, matrizes de horários, tabelas, quadro de horários fixos do que fazer em cada intervalo ou espaço 
de tempo e até mesmo a flexibilização em determinados dias da semana. Esses são alguns exemplos que marcam a organização formal e real do tempo escolar.

Entretanto, para esta proposta de investigação, o Ritmo Formal e Real foram desenvolvidos no mesmo espaço conceitual, ou seja, no espaço do Ritmo Formal. Traçou-se uma linha investigativa na qual foi analisado o Ritmo Escolar exclusivamente por meio do viés Formal e Oculto. Desse modo, toda vez que for mencionada a organização do Ritmo Formal neste trabalho, o leitor precisa ter claro que estão abarcadas tanto as questões legais quanto as reais do tempo do funcionamento da escola. Em efeito, se ambas as formas de apresentação e interpretação curricular são distintas (Formal e Real) elas ainda estão interligadas pela mesma lógica organizacional: ora o Ritmo/Currículo Real é, de certo modo, uma adaptação local de uma orientação legal, ou seja, de um Ritmo/Currículo Formal.

Quanto ao Ritmo Oculto, segundo Gonçalves (1994), Philip Jackson, estudioso norteamericano, foi o primeiro a utilizar o termo "currículo oculto" para incorporar as questões de organização de espaço e tempo, para além do currículo formal. No Brasil, Lopes e Macedo (2011, p. 32) afirmam que:

[...] há um ótimo exemplo de currículo oculto inscrito na própria forma como os currículos são organizados e pensados. Ao optarem por modelos sistêmicos para a definição do que e como ensinar, tais perspectivas assumem o fazer curricular como questão técnica, científica, ocultando a dimensão ideológica presente nessa seleção.

Esta perspectiva fica evidente quando a organização curricular apresenta a preocupação com o tempo escolar. No Brasil, a obrigação legal exige que o tempo de escola se cumpra em 200 dias letivos e 800 horas, sendo 4 horas-aulas diárias, as quais podem sofrer alterações a fim de proporcionar até 7 horas diárias conforme as possibilidades e parcerias estabelecidas entre prefeituras, estados e governo federal (BRASIL, 1996). Cabe, portanto, a cada município e escolas se organizarem para o cumprimento da lei. Contudo, na maioria dos casos, as atividades escolares (majoritariamente aulas tradicionais com um professor regente) ocorrem em 4 horas diárias e as demais etapas da EB funcionam organizadas por turnos. Uma mesma escola pode acolher em turnos diferentes (manhã, tarde e noite) as distintas etapas.

Na França, o funcionamento das escolas é fundamentado em dois modos básicos que se constituem na decisão de ofertar ou não ofertar aula às quartas-feiras no período da manhã. Dessa forma, as escolas públicas que ofertam aula na quarta-feira pela manhã, funcionam quatro 
dias e meio por semana e têm, em média, 180 dias letivos por ano. Por outro lado, as escolas que não ofertam aula às quartas-feiras, funcionam quatro dias por semana e, portanto, o número de dias letivos reduz para uma média de 144 dias anuais. O mais importante, na França, é analisar o número de horas de aula por dia, sendo que em um sistema de quatro dias e meio de aula, nove turnos por semana, deve-se respeitar a máxima de $5 \mathrm{~h} 30 \mathrm{~min}$ por dia e $3 \mathrm{~h} 30 \mathrm{~min}$ por turno. Em um sistema de quatro dias de aula deve-se respeitar a máxima de 6h de aula por dia, sendo no máximo $3 \mathrm{~h}$ de aula por turno. Ambos os sistemas devem obedecer a máxima de $24 \mathrm{~h}$ de aula formal por semana (FRANÇA, 2017).

Tanto a França quanto o Brasil apresentam, nacionalmente, duas formas de distribuição do tempo/atividades para as escolas e mantenedoras seguirem e organizarem os seus Ritmos Escolares. Os países, portanto, reforçam, centralizam e formalizam certas proposições de organização de horários e atividades e, conforme aponta Palamidessi (2002, p. 119), apresentam “[...] um certo número de distribuições possíveis; uma matriz que precisa ser atualizada, concretizada e adaptada [...]" pelo poder local em conjunto com suas escolas.

Destarte, os ajustes no tempo legal podem ser compreendidos no Brasil e na França como formas de manifestação do Ritmo Formal: mede-se o ritmo de uma escola, sua intensidade e funcionamento a partir de seu quadro de horários e atividades em uma jornada diária, semanal ou até mesmo anual.

Porém, sob uma perspectiva crítica curricular, é preciso considerar que tudo que se refere ao currículo está involucrado pelas relações de poder, pelas diferentes formas de organização social. Sendo o Ritmo Escolar um componente curricular, a forma como ele existe não é, portanto, inocente e neutra. Significa, portanto, que sua existência não é uma proposição de organização somente técnica. Pois:

Embora questões relativas ao "como" do currículo continuem importantes, elas só adquirem sentido dentro de uma perspectiva que as considere em sua relação com questões que perguntem pelo "por quê" das formas de organização do conhecimento escolar (MOREIRA; SILVA, 1995, p. 7).

O Ritmo Escolar, por se tratar de um componente curricular, está carregado de sentidos, histórias de crenças e de relações de poder que se manifestam, tanto nas práticas escolares, que realizam os professores em sala de aula, quanto na forma que respondem os alunos ao que lhes é dado pela escola, dentro da própria escola. 


\section{RITMO OCULTO}

Só se pode entender de fato como funcionam os Ritmos Escolares a partir de uma percepção de como se dão as relações no espaço da escola, na sala de aula, nos tempos de atividades físicas, na hora do lanche e até mesmo nos "por quês" da realização de determinadas atividades e práticas pedagógicas dentro de um espaço formal de tempo escolar.

Observou-se no Brasil, por exemplo, que na quinta-feira os alunos dos $5^{\circ}$ anos usufruíram de atividades escolares diferenciadas, no turno regular de aula, pois havia o Dia do Planejamento para os professores regentes. Contudo, por mais que houvesse um dia da semana no qual as turmas usufruíam de atividades diferenciadas, com aula de Inglês, Ensino Religioso e Educação Física, em uma organização formal do tempo, nem sempre estas atividades ocorriam da forma como deveria. Constatou-se que a falta do professor regente fazia com que os alunos não valorizassem a presença do professor da área específica; os professores tinham dificuldade para controlar a agitação dos alunos, fazendo deste dia mais um laisse-faire do que um dia de aulas especializadas como o que era pretendido formalmente. Os professores geralmente davam atenção aos alunos que eles julgavam que "queriam aprender" e os demais não eram envolvidos nas aulas, permanecendo em suas classes sem nenhuma atividade.

Na França, mesmo que houvesse um Ritmo Escolar Formal que obedecesse a lógica aula formal/ tempo do meio-dia/ aula formal/ e atividades extracurriculares, a participação das crianças nas atividades extracurriculares no tempo do meio-dia e do fim de tarde dependia dos fatores socioeconômicos das famílias, por exemplo. Não obstante, as atividades que eram desenvolvidas nos ateliês e nos tempos extracurriculares construíam saberes que não se relacionavam com as atividades de sala de aula. Existiam dois tipos de tempo: o de escola e o de lazer que embora compartilhassem espaço e tempo, ou seja, o espaço da escola e o tempo na escola, não possuíam ligação e não dialogavam entre si.

A partir dessas variações de funcionamento das aulas, compreendeu-se que o Ritmo Escolar, para além da apresentação formal de atividades (Ritmo Formal), se materializa nas relações do cotidiano escolar e carrega sentidos ocultos ao programa escolar (Ritmo Oculto). Este tipo de distinção entre "formal" e "oculto" está expresso nas discussões educacionais relativas ao currículo através de uma diferença entre Currículo Formal e Oculto.

Quando Perrenoud (2013) anuncia que o ofício de ser aluno está condicionado a uma série de exigências que vêm da escola para o aluno, que deve saber ser, fazer e cumprir as tarefas 
exigidas para que seja garantido seu sucesso escolar e, consequentemente, seu sucesso social, ele remete a antigas discussões educacionais. Bourdieu e Passeron (1970) afirmaram que a escola, no momento de avaliar ou selecionar seus alunos, exige posturas, formas de ser que vão além do que está expresso nas listagens de conteúdos escolares e que, consequentemente, os alunos que não correspondem às expectativas exigidas pela escola possuem uma grande tendência a exclusão, seja em função de negligência da escola para com eles, seja porque eles mesmos irão se autoexcluir por pensarem que não são bons alunos.

Ora, sabe-se que esta forma dogmática de entender o funcionamento escolar não contribui efetivamente para uma mudança de paradigmas sobre a escola tradicional e, ao contrário, reforça a ideia de que há uma violência simbólica que é parte da escola. Contudo, isso não deixa de contribuir para a compreensão de como é, de como se desenvolve e de como ainda vive o sistema educativo, seja na Suécia, no Brasil, na França ou em outras partes do mundo. Por certo, a escola está carregada de formulações, recomendações, organizações técnicas de seu funcionamento em que os alunos devem buscar as maneiras de se adaptar.

Os Ritmos Escolares fazem parte, portanto, de uma discussão internacional, pois mesmo em uma mirada comparativa, o Ritmo Escolar é visto como um componente curricular. Problematizado a partir de uma perspectiva crítica, vai além de uma simples organização técnica do tempo que alunos e professores passam na escola e na sala de aula. O Ritmo Escolar manifesta os sentidos dados por eles sobre o tempo de se estar na escola e o modo de perceber as relações de poder entre os sujeitos escolares dentro dos diferentes tempos de atividades escolares.

\section{NEGOCIATAS DO TEMPO: UMA APRESENTAÇÃO PRÁTICA DO COTIDIANO DE UMA TURMA BRASILEIRA}

A Turma do $5^{\circ}$ Verde foi observada no contexto da $(\mathrm{EBr})$ e tinha 26 alunos, a idade média dos alunos era de 13 anos. A organização semanal das aulas estava distribuída em cinco dias da semana, das $7 \mathrm{~h} 45 \mathrm{~min}$ às $11 \mathrm{~h} 50 \mathrm{~min}$, com um intervalo regular de $20 \mathrm{~min}$ e um lanche de mais 20min. Apenas nas quintas-feiras a turma tinha as disciplinas específicas: Ensino Religioso, das 7h45min às 9h30min; Educação Física, das 10h10min às 10h55min e Inglês, das $10 \mathrm{~h} 55 \mathrm{~min}$ às $11 \mathrm{~h} 50 \mathrm{~min}$. 
A Turma Verde era classificada pelos professores como uma "turma agitada". O primeiro desafio apontado pela regente Lucimara diz respeito à falta de respeito dos alunos com relação às regras das aulas. Além da regente, durante as observações, foi possível conhecer três outras professoras que faziam parte do Dia do Planejamento às quintas-feiras: a de Inglês, a de Ensino Religioso e a de Educação Física. Todas elas mencionaram descontentamento com a turma. Muitas vezes, as professoras só conseguiam a atenção e o silêncio dos alunos nos cinco minutos anteriores a ida para o pátio, pois haviam negociado que "os levariam para o pátio" se "copiassem e fizessem tudo". Para outras, a troca estava em uma ameaça de registrar o mau comportamento do aluno no caderno de ATAS, levar um bilhete no caderno, chamar os responsáveis ou deixar sem recreio. O desenrolar das aulas dependiam de negociatas, de saída mais cedo para o pátio, da luta pelo recreio ou dos bilhetes no caderno.

O Ritmo na Turma Verde era permeado de negociatas entre o momento inicial, quando todos os alunos copiavam/realizam as tarefas em seus cadernos, enquanto, paralelamente, havia brincadeiras que se desenvolviam entre os alunos, provocações, agitações entre eles, que de certa maneira atrapalhavam o desenrolar do plano organizacional de Lucimara. As atividades variavam entre ler um texto, interpretar questões, separar sílabas e classificar em oxítona, paroxítona, proparoxítona, contar de dez em dez, de cem em cem, dividir, multiplicar, descobrir o antecessor e sucessor, interpretar histórias matemáticas, entre outras.

$\mathrm{Na}$ medida que os alunos iam perdendo interesse pelas atividades, a professora necessitava intervir e aumentava seu tom de voz para pedir silêncio e assim restaurar a ordem da aula. Algumas vezes, como dito, era necessário, além de aumentar a voz, tomar medidas de punição mais severas para retomar a atenção dos alunos para o quadro e para seus respectivos cadernos.

Charlot (2013) compreende que essas relações entre os alunos e as professoras são, muitas vezes, regidas pelas resistências entre ambos os lados e expressam lutas e defesas de interesses dentro do espaço da sala de aula. O professor, na perspectiva tradicional, se reconhece como um profissional que age tentando respeitar o plano de estudo e conteúdo da escola, dentro de um determinado período de tempo, buscando os métodos e estratégias para negociar com os alunos a execução dos conteúdos, mesmo que isto não signifique a aprendizagem da matéria por eles. O tempo das aulas se deturpa e o objetivo principal deixa de ser um tempo de aprendizagem e passa a ser um tempo de buscar os meios de fazer com que os alunos 
bagunceiros “não atrapalharem os que querem fazer", bem como não atrapalhar o plano de aula que o docente propôs para o dia. Na entrega de boletins, também, pôde-se revelar esse tipo de desejo, quando Lucimara reportou aos responsáveis presentes que seu maior desafio com a turma era manter o caderno em dia. Para Lucimara:

A questão assim ó. Muitas vezes eu sei que eles não gostam de certas atitudes
que eu tomo dentro da sala de aula com eles. Mas assim ó. Eu coloco pra vocês
que são pais avós, né. Vocês querem o bem dos filhos de você, dos netos de
vocês, não é? Vocês querem o melhor pra eles, né? Eu, como professora, eu
também quero isso. Então, muitas vezes é necessário que eu seja exigente, que
eu seja durona que eu faça todas essas anotações e que não é positivo dentro
da sala de aula. [...] Então assim ó. Eu sempre digo se eles chegarem em casa
reclamando "a professora ficou 5 minutos do recreio comigo copiando as
coisas". Vou ficar se for necessário porque eu acho assim como é que o aluno
vai estudar com o caderno incompleto? Né? Vocês querem que os filhos de
vocês avancem. Eu também, como professora, eu quero. [...] É proibido comer
chiclete? Então, não vai comer. É proibido usar boné na sala de aula? É. Então,
não vai usar. São regras que a escola tem. A gente tem que cumprir, assim
como tem as regras lá de casa tem a regra da escola. Futuramente vocês vão
tá trabalhando. [...] Então, eu acho que tem que começar agora a ter né seguir
essas regras.

Nesta fala nada neutra, a cobrança da professora apresenta seus fins e objetivos ocultos, mas explícitos a partir de uma visão crítica: o professor será o primeiro patrão, o ensino oculto será voltado para responder às demandas do mercado e a introjeção da ideia de que a escola é para preparar para a vida adulta, a vida do trabalho, a subserviência diante do patrão. Assim, a aprendizagem incidental acaba contribuindo para uma socialização social, política do estudante com formas de viver, valores e trabalhos específicos (APPLE, 1982).

O Ritmo das aulas é carregado de negociações com o intuito de trabalhar para a ordem, para o caderno em dia, para o comportamento, para copiar de forma rápida e eficaz, pois a "professora quer passar mais no quadro" e se o aluno conseguir mostrar que pode manter-se em silêncio, durante o tempo de aula, é concedido um tempo de liberdade, o recreio, o pátio ou a não punição. Logo, os tempos do recreio e do pátio, que são elementos formais do Ritmo Escolar passam a ser recompensa, material de negociação e não tempo de recreação. É preciso sacrificar o tempo da diversão indo à escola e até mesmo o tempo de diversão que a escola propõe; se você não se comportar o tempo tratará de te penalizar. 


\section{O RITMO COMO UMA IMPOSIÇÃO NO TEMPO: O CASO DA FRANÇA}

A Turma Vermelha, na França, também era composta por 26 alunos, todos com uma média de oito e nove anos de idade. A família de $99 \%$ dos alunos não era originária da França, sendo que desses 11 não tinham nascido no país. Na turma, havia três alunos que frequentavam uma classe diferenciada chamada, em francês de Unités Pédagogiques pour Élèves Allophones Arrivants (UPE2A), em português, Unidade Pedagógica para Alunos Recém-chegados Alófonos, destinadas à alfabetização de alunos que não falavam francês e acabavam de se integrar no país com o status de imigrante.

Melanie, a regente, relatou que era necessário que ela organizasse um planejamento de atividades diárias, que deveriam funcionar em compatibilidade com os horários da UPE2A, uma vez que as aulas ocorriam concomitantemente ao horário das aulas regulares. Logo, ela possuía uma organização do tempo de suas aulas, em que pela parte do começo da manhã e começo da tarde (antes da recreação), eram realizados os exercícios de francês, ortografia, gramática, leitura, enquanto seus alunos imigrantes iam para a UPE2A e na segunda parte (após a recreação), os exercícios de matemática, artes, esportes que, segundo Melanie, os alunos não falantes do francês não tinham dificuldade em realizar e poderiam participar.

Se o caráter das origens chama atenção na constituição da escola, segundo Mélanie o seu maior desafio na turma não está na linguagem. Para ela, o desafio estava em ter a atenção das crianças durante todo o tempo de aula, porque a forma como está organizada a jornada escolar desiquilibrava a sua aula e, sobretudo, fazia com que os alunos no turno da tarde fossem bastante desatentos. Para poder entender Mélanie é necessário observar os horários de funcionamento da escola, cujas atividades iniciavam às $8 \mathrm{~h} 45 \mathrm{~min}$ e terminavam às $16 \mathrm{~h} 1 \mathrm{~min}$, com exceção da quarta-feira quando entravam às $8 \mathrm{~h} 45 \mathrm{~min}$, mas saiam às $12 \mathrm{~h}$. As atividades possuíam um intervalo entre às $12 \mathrm{~h}$ e às $14 \mathrm{~h} 15$, para o almoço, com uma pausa que totaliza $2 \mathrm{~h} 15 \mathrm{~min}$ de intervalo antes de a aula começar pela tarde. Segundo Mélanie, este tempo de pausa era bastante longo e influía no comportamento das crianças no turno da tarde, na aula regular, uma vez que elas eram mais agitadas e não conseguiam se concentrar. Vejamos:

Rosa: Como você caracteriza sua sala de aula? Os alunos?

Melanie: São alunos bastante simpáticos, mas que têm dificuldade em escutar. Eu colocaria isso mais sobre o feito que. Isso que eu te dizia. Em nível de ritmo, não se convém pra nada. Eu tenho a impressão realmente que cada vez mais piora. É talvez porque eu começo a envelhecer, mas eu penso realmente que, por exemplo, essa ideia 
de fazer ateliês no meio dia. "A gente termina meio-dia, a gente faz ateliê, a gente come, a gente joga um pouco, a gente vem pra escola", realmente, é um pouco qualquer coisa.

Em todos os dias de observação, Mélanie mencionou que para ela era bastante difícil trabalhar no período da tarde, que era difícil realizar uma atividade de concentração nesse turno. Não obstante, nossas observações revelaram uma turma bastante silenciosa, os alunos não falavam muito entre si e, na maioria do tempo, obedeciam às regras propostas por ela. $\mathrm{O}$ maior pico de agitação observado foi durante as aulas de Educação Física em que os alunos se empolgavam com as atividades e acabavam se dispersando no momento de ouvir as regras dos exercícios.

A turma estava na fase de aprender os sons das letras, as atividades propostas pela regente consistiam em: ditados de palavras e frases, sublinhar palavras no texto ditadas pela professora, cálculos mentais, exercícios de alfabetização de interpretação em folhas, leituras de palavras em voz alta, exercícios de repetição.

Percebeu-se a existência de uma pedagogia do silêncio na aula, na qual existia uma hierarquia entre Mélanie e os alunos e que é naturalizada entre ambos. A autoridade do professor em sala de aula faz com que o aluno fique notoriamente em silêncio, que eles façam as atividades, não há atrasos nas atividades e todos acabam praticamente juntos. Todos seguem a sequência da aula. Mélanie diz "começamos" e todos começavam a fazer a atividade, ela usa expressões como "vamos, a gente vai começar", "temos que começar agora", "se você não começar agora você vai ficar para trás e terá que se virar sozinho".

No turno da manhã, os alunos eram mais silenciosos que à tarde, mas ainda assim, não se tratava de conversas de alto tom entre as crianças, nem movimento ou desrespeito entre as crianças da sala. Logo, entende-se que havia um parâmetro de barulho, de conversa, de ser aluno que se impunha sobre o tempo de aula e este era bastante restrito.

Um aporte tradicional do Ritmo Escolar pode ser classificado no contexto da Turma Vermelha da mesma forma que no contexto da Turma Verde. Mesmo que os mecanismos de organização e de ordem do tempo fossem diferenciados, o objetivo fundamental das ações que se desenvolviam estava em realizar as atividades propostas, de respeitar o tempo de aula.

A análise da organização tradicional do tempo de funcionamento da aula regular denuncia o Ritmo Oculto: o silêncio grita na Turma Vermelha. Não há acordo e negociatas, como no caso brasileiro, mas o estresse dos alunos fortemente defendido por Mélanie, a 
desatenção das crianças, as três vezes em que choraram na sala, a busca pela defesa fiel da ideia de que a aula é tempo de trabalhar, que se deve estudar, ouvir, realizar a tarefa, gritam a imposição de um Ritmo Escolar tensionado, pressionado. A gestão do tempo pelo professor coloca o aluno em posição paradoxal dentro do Ritmo Escolar: começar, mas não se mexer, não falar, ficar em silêncio no tempo de aula. Mélanie é a mestre da orquestra do Ritmo Escolar, mas será que os alunos são os músicos? Será que eles tocam seus instrumentos?

\section{MAIS OU MENOS EDUCAÇÃO?}

A jornada escolar brasileira é, na maioria dos casos, de 4hs. Assim, o "Novo Mais Educação ${ }^{3 "}$ funciona como uma proposta de ampliação da jornada escolar brasileira em $5 \mathrm{~h}$ ou 15h semanais. Sendo que para cada opção, a escola deve ofertar certos tipos de atividades. Para a opção de 5h deve-se propor atividades de acompanhamento pedagógico, sendo a de Língua Portuguesa e a de Matemática, com 2h30min de duração cada. Para a opção de 15h, deve-se ofertar as mesmas atividades de acompanhamento pedagógico, com duração de 4 h cada uma e, também, $3 \mathrm{~h}$ de atividades as quais visem temas culturais, artísticos, de meio ambiente, físico entre outras áreas do conhecimento (BRASIL, 2017a).

$\mathrm{Na} \mathrm{EBr}$, adotava-se a opção de $15 \mathrm{~h}$, ofertado no turno inverso das aulas regulares. Contava com dois mediadores e quatro monitores, sendo estes: um mediador de Português (doutoranda em Tecnologia dos Alimentos) e de Matemática (graduando de Educação Física), um facilitador de Dança (graduando de Dança), um facilitador de Educação Física (graduando de Educação Física) e dois facilitadores de Educação Ambiental (graduandas de Geografia).

Nesta pesquisa, observaram-se as ações da mediadora de Português, Carla, no turno da tarde, quando eram desenvolvidas as atividades com os alunos dos anos finais do ensino fundamental e do $5^{\circ}$ ano escolar dos anos iniciais. Doutoranda em Tecnologia dos Alimentos, ela realizava atividades de Português com os alunos, pois possuía formação em nível superior, requisito aceito pelo Programa para realizar esta proposta. As atividades tinham duração de $3 \mathrm{~h}$, quando pela manhã, no horário das 8 h45min às $11 \mathrm{~h} 45 \mathrm{~min}$, quando pela tarde, das 14h10min às 17h10min, distribuídas de segunda a quarta com 1h para Educação Ambiental, 1h para Matemática e 1h para Dança; nas quintas-feiras, 1h30min para Português e 1h30min para Educação Física; nas sextas-feiras, 1h30min para Dança e 1h30min para Educação Física, com lanche de $10 \mathrm{hmin}$ pela manhã e 15 min pela tarde. 
Se a formação dos profissionais que realizam as atividades chama atenção, elas são explicadas pelo coordenador Lucas devido ao baixo salário pago para essas funções. $\mathrm{O}$ pagamento dos mediadores e facilitadores é feito pelo número de turmas que eles atuam. As turmas de Português e Matemática, que contam com mediadores, o valor é de $\mathrm{R} \$ 150,00$ por turma. Para as atividades dos facilitadores, o valor pago é de R\$80,00 (BRASIL, 2017b). Segundo o coordenador Lucas, os critérios para selecionar os candidatos tiveram de ser flexibilizados, pois ao saberem o valor pago, pessoas formadas na área da educação desistiam do trabalho.

As atividades do programa eram realizadas dentro da escola em um pequeno pavilhão que continha cinco salas de aula e um grande hall de entrada. O local era um espaço inutilizável, com bastante pó, algumas cadeiras e materiais em mau estado. Nas salas de aula, havia um quadro negro, mesas e cadeiras em formato de uma sala de aula tradicional. No salão havia armários com materiais guardados, alguns jogos, computadores velhos e não utilizáveis. As atividades ocorriam em dois turnos, pela manhã, recebiam-se os alunos que tinham aula regular pela tarde e vice-versa. Ao total eram 200 alunos cadastrados, sendo que destes 53 participam de forma efetiva do programa. As razões para o pouco número de participantes se dá por três motivos relatados por Lucas: primeiro, a necessidade que alguns alunos tinham, sobretudo das séries finais, de ajudar nos afazeres da casa. Isto se dá porque havia um grande número de meninas matriculadas nos anos finais e, no contexto de uma cultura machista, elas eram escaladas por suas famílias para cuidar dos irmãos que ficavam na creche só meio turno.

Outra justificativa para o pouco número de alunos que frequentam é a falta do almoço e do lanche entre os turnos. Em junho de 2017, durante o desenvolvimento de nossas observações, a verba da merenda não havia ainda chegado à escola. Assim, os alunos nos momentos de intervalo não tinham lanche oficial e quando o tinham eram bolachas, distribuídas dentro da sala e que vinham da merenda do turno regular, bem como não tinham o almoço. Logo, muitas crianças não vinham para as atividades do contra turno, pois não havia o almoço do meio-dia e, ao retornarem para suas casas, não voltavam no turno da tarde, sobretudo, porque a maioria das crianças morava em invasões que, mesmo localizadas no bairro da escola, ficavam longe, demandando cerca de 20 ou 30 minutos de caminhada. A mediadora Carla relata ${ }^{4}$ como a merenda era organizada quando faltava lanche: 
Rosa: Eles não estão ganhando o lanche da tarde?

Carla: Não. Eles não tão ganhando. E eles reclamam um monte "tô com fome, tô com fome". E como é uma região bastante humilde, tem crianças que não trazem nada para comer ou até mesmo não tem nada para comer. Então é complicado. [...] Eu sempre digo para eles trazerem lanche. Digo "qualquer coisa que vocês tiverem em casa". Não interessa o que for. Mas, ninguém vai ficar "ah tu trouxe" ninguém vai ficar. Eu sempre digo para eles, mas eles, muitas vezes, não têm o que trazer e não trazem. Daí de vez em quando, de vez em quando, quando a gente pode a gente pega bolacha lá na cozinha e dá umas três bolachinhas para cada um. Ou de vez em quando eu também faço aquilo que eu digo que é "lanche coletivo" sabe. Que daí eu digo "cada um traz alguma coisa, pode ser qualquer coisa" e daí a gente faz lanche coletivo, inclusive eu trago e daí a gente lancha junto. Eles adoram. Só que tem muitos que não trazem porque não tem também. Só que aí eu não tiro, não deixo eles sem participarem porque não dá né.

Ainda assim, na conjuntura da $\mathrm{EBr}$, o almoço era somente para os alunos que frequentavam o Novo Mais Educação pelo turno da manhã, ou seja, os alunos do $2^{\circ}$ ao $4^{\circ}$ ano da escola que tinham aula no turno da tarde. Existiam algumas exceções nos casos de alunos com irmãos ou que são bastante carentes. Estes almoçavam na escola e não retornavam para casa. A não oferta do lanche para os alunos dos anos finais, que frequentam a aula regular pela manhã, era explicada pelo fato de o projeto no turno da tarde começar às 14h10. Então, segundo o coordenador Lucas, eles teriam tempo para ir até suas casas, almoçar e voltar.

A terceira justificativa para a pouca frequência advinha do fato de que muitas famílias não se interessariam em matricular seus filhos nas atividades extraescolares, pois eles se sentiam acuados ou pouco integrados com o espaço da escola. Logo, era difícil ter a participação de todas as crianças, para Lucas:

Porém muitos desses alunos ou por questões de abandono em casa mesmo. Tu percebe que esses problemas que as crianças têm psicológicos de aprendizagem às vezes não vêm do nada. Eles vivem num convívio onde as pessoas meio que abandonaram eles, sabe. Aí tu conversa com as mães "ele precisa é importante pra ele, o momento que ele vai". O aluno tem problema, ele tá no $4^{\circ}$ ano e ele não consegue reconhecer palavras, letras. A professora do $4^{\circ}$ na está preocupadíssima como o que esse aluno não consegue. [...] Mandei a autorização no outro dia "cadê a autorização assinada?" "não, minha mãe não assinou". Aí liguei pra mãe. "A senhora não assinou?" "Esqueci de assinar". Aí, tá: "vai de novo aí a senhora assina, daí" Daí no outro dia veio assinado. "Tá bom agora ele já pode vir de manhã pro mais educação". Aí ele nunca veio. Liguei pra mãe de novo "ele não vai vir no Mais Educação" "não, eu não tô conseguindo mandar". 
O cotidiano das atividades desenvolvidas no Programa começava com os temas de casa. Carla, primeiramente, perguntava quem tinha temas e os auxiliava nos exercícios. Os alunos que não tinham temas, geralmente, ficavam conversando ou realizando alguma atividade com folha. Após terminar os temas de casa, a mediadora apresentava algum conteúdo que deveria ser realizado exercícios sobre ele, como: a introdução do conceito de adjetivo, noção de sílaba tônica, separação de sílabas, encontro de vogal e consoante.

A turma observada era composta por alunos com idade entre 10 e 13 anos, quase todos oriundos dos $5^{\circ}$ anos da escola e poucos das demais séries finais. Os alunos agrediam-se verbalmente e fisicamente durante a aula e, na maioria das vezes, no turno extraescolar se reproduzia as mesmas situações de negociatas e forma de intervenção da mediadora Carla, tal como Lucimara fazia: "Comportem-se! Vamos fazer as atividades. Se ficarem em silêncio, saímos para o pátio". Assim, no segundo período, após o recreio, a configuração era clássica: os meninos iam jogar bola, as meninas iam pular corda ou caminhar de braços dados no pátio.

Quanto à aprendizagem, as observações revelaram que nos momentos de introdução de um novo conteúdo, os alunos que tinham certo domínio da leitura e da escrita conseguiam realizar as atividades de uma maneira mais fácil do que os que tinham dificuldades nestas habilidades. Assim, o tempo das aulas era mais bem aproveitado, em termos de conteúdos curriculares e sociabilidade, pelos alunos que conseguiam assimilar a matéria do currículo escolar. Isto porque a monitora reproduzia, num espaço de tempo destinado a ser diferente do da escola, os mesmos mecanismos de dominação que as professoras nas classes regulares.

Analisando as consequências e sentidos subjacentes à organização das atividades extraescolares na EBr, a organização formal do tempo extraescolar carrega em si dificuldades estruturais que reforçam os mesmos problemas do cotidiano formal da escola: falta de investimento, professores sem formação adequada para atender às necessidades das crianças e jovens, atividades fragmentadas em horas e tempos específicos, são alguns exemplos.

Nesta pesquisa não se nega a legitimidade dos programas de alargamento e melhoramento do tempo de escola e o compromisso que estes assumem não só com o processo de aprendizagem, mas, também, com o caráter de justiça social, uma vez que não se pode negar o peso das desigualdades sociais na aprendizagem das crianças oriundas de camadas mais populares no Brasil. Contudo, se a relação estabelecida se refere, somente, à aprendizagem dos alunos e à incorporação dos conhecimentos escolares dentro de um "novo" tempo de escola, as 
propostas de alargamento ficam um pouco limitadas e vazias de sentido social. Questiona-se, por fim: Mais Educação com menos educação?

\section{TEMPO DO MEIO-DIA, ATIVIDADES PÉRISCOLAIRES: E O TEMPO DE SER CRIANÇA ONDE FICA?}

Na França, atualmente, cada cidade pode escolher em qual tipo de modelos de Ritmo Escolar as escolas públicas irão funcionar. Na cidade de Rennes, as escolas públicas obedecem à organização de uma jornada escolar de quatro dias e meio, ofertando o TAP e o tempo do meio-dia. É importante salientar que há uma diferenciação sobre a homogeneidade de funcionamento entre público e privado. Nas escolas privadas, cabe a elas decidirem a forma como organizarão seus Ritmos Escolares. Logo, em um mesmo município, como é o caso de Rennes, as escolas privadas trabalham no formato da semana de quatro dias sem a oferta dos TAP e as públicas com a semana de quatro dias e meio e com oferta dos TAP.

O tempo périscolaire propõe atividades extracurriculares que complementam o roteiro escolar diário, com a oferta de oficinas diferenciada no tempo do meio-dia e após o fim das aulas no turno da tarde dentro da escola. O almoço escolar é outra forma de atendimento proposta para as crianças que precisam ficar durante o tempo do meio-dia. O almoço é fornecido pela prefeitura, servido na escola e é pago pelas famílias dos alunos. $\mathrm{Na} \mathrm{EFr}$, o pagamento do almoço incluía a refeição e as atividades do fím da tarde (TAP). O preço médio do pacote “almoço + TAP" era de $1 €$ por dia para as famílias que possuíam ajuda social e de baixa renda, mas a tarifa podia ir até $5 €$ dependendo da renda e também da escola.

Isso significa que as crianças que almoçavam na escola e participavam do TAP do fim da tarde eram, fortemente, as que podiam pagar. Segundo Charlotte, coordenadora do TAP, cerca de 170 crianças, de um total de 270 matriculadas almoçavam na escola. Ainda assim, não é possível afirmar que todas as que não almoçavam não o faziam por condições financeiras, mas entendia-se que este fator era importante na escolha ou não do almoço, pois a maioria das crianças que comiam na escola e ficavam até tarde eram aquelas cujos pais trabalhavam.

$\mathrm{O}$ almoço era servido em dois momentos: às $12 \mathrm{~h} 15$, para alunos do $1^{\circ}$ até o $3^{\circ}$ ano e às 13h, para alunos do $4^{\circ}$ e $5^{\circ}$ ano. Entre os dois horários, os alunos que não estavam almoçando participavam das oficinas do meio-dia. Durante o período de observação de 09 a 22 de dezembro de 2017 foram oferecidas oficinas de montagem de materiais recicláveis, oficina de 
leitura, dança, jogos esportivos, jogos coletivos, multiesportes, bijuterias e artesanatos brasileiros, jogos de sociedade e pixel e arte. Estas, eram gratuitas e podiam ser frequentadas, no segundo turno, pelos alunos que almoçavam em casa. Nessa conjuntura, havia alunos que saíam da escola, iam almoçar em casa e voltavam no horário das $13 \mathrm{~h} 15$ para as oficinas gratuitas. A tarifa a pagar, neste caso, era menor. Contudo, vale contextualizar que a escola estava localizada no fim um conjunto de prédios sociais, e as crianças que a frequentavam, diferentemente do contexto de Santa Maria, caminhavam alguns poucos minutos para se deslocarem da porta do prédio até a escola. Em muitos casos, a janela da casa encontrava a janela das salas de aulas.

As atividades do tempo do meio-dia contavam, além da coordenadora, com oito animadores: uma concursada (responsável por uma oficina de montagem com materiais recicláveis e auxiliar da coordenadora na gestão das crianças); um de leitura, que também ofertava uma oficina de jogo de sociedade; um de outra oficina de montagem; dois de dança; um de jogo coletivo; um de jogos esportivos, que também ofertava uma oficina de jogos de sociedade; um de jogos coletivos, que também ofertava uma oficina de multiesportes e, por fim, um de pulseiras brasileiras que também ofertava uma oficina de pixel e artes. Todos eles possuíam alguma formação oficial na área de animação de crianças e jovens.

Os animadores que são contratados, não concursados, têm um salário que é em média de $900 €$ e se configura como trabalho intermitente. Esta função tem por tendência durar todo o ano escolar e se finda no começo de cada período de férias, sendo renovada em cada volta às aulas $^{5}$. Sendo assim, durante as férias, se estes animadores não trabalham na colônia de férias ofertada pela prefeitura, elas estão automaticamente sem salário.

No contexto das observações, normalmente, às 14 hs encerravam-se as oficinas e almoço e as crianças iam para o pátio da escola brincar até o sinal tocar. As aulas formais retornavam às $14 \mathrm{~h} 15$ e terminavam às $16 \mathrm{~h} 15$, com exceção da sexta-feira quando terminavam às $16 \mathrm{~h}$. Vale ressaltar que algumas das atividades TAP funcionam em regime de parcerias com associações externas. Logo, havia profissionais de associações culturais do bairro ou da cidade que iam até a escola para propor as oficinas. Elas começavam às $17 \mathrm{~h}$ e terminavam às $18 \mathrm{~h} 30 \mathrm{~min}$ e os alunos participavam de uma atividade diferenciada por dia, que deveria ser acordada entre família e coordenação. Durante o tempo das $16 \mathrm{~h} 15$ até o início do TAP as crianças ficavam uns 15 minutos no pátio realizando uma segunda recreação. Depois, tomavam um lanche trazido de casa e, por fim, tinham apoio para a realização dos temas que eram ofertados pelos animadores 
do tempo do meio-dia. Alguns dos animadores do tempo do meio-dia, também atuavam no TAP e cuidavam da recreação. As atividades oferecidas eram: ginástica, atividades criativas de chinês e atividades científicas nas segundas-feiras; futebol gaélico, escultura, teatro e Scarbooking, nas terça-feiras; Hokey, vídeo e horta no prato, nas quintas-feiras e Rugby, criação de bijuteria e costura, nas sextas-feiras.

As observações diretas ocorreram, no tempo do meio-dia nas atividades de dança, e, no TAP da oficina de vídeo e, assim como no Brasil, não se focalizou em observar os alunos da Turma Vermelha e sim o conjunto de crianças que participam das atividades. No que concerne a atividade de dança, o grupo que participava era de 12 alunos, todas meninas de múltiplas idades dos 7 aos 12 anos que estavam na fase inicial e final da escola.

$\mathrm{Na}$ atividade do vídeo, a turma era composta por 12 alunos. No contexto da oficina de vídeo, os alunos estavam aprendendo a gravar e fazer entrevistas em vídeo com o animador. No dia da observação, os alunos estavam olhando as gravações que eles mesmos tinham produzido nas aulas anteriores e que o animador havia editado para mostrar a eles. As gravações consistiam em elaborar perguntas e entrevistas para um colega e, ao mesmo tempo, gravá-lo em vídeo. Foi uma atividade de muitas risadas e, muitas vezes, gargalhadas altas, pois os alunos viam a si mesmos e os seus demais colegas em vídeo e achavam a situação engraçada.

As duas atividades observadas mostraram um cotidiano de bastante interação e engajamento entre animadores e alunos nas atividades. Não obstante, algumas situações e falas revelaram alguns desafios que permeiam o TAP. Primeiro, no pátio, nas atividades do meio-dia e do TAP, percebeu-se um grande número de agressões, chutes, gestos de violência entre os alunos. Tais ações não foram percebidas no espaço e tempo das aulas formais. Nas filas com os animadores era possível visualizar que alguns tinham dificuldade de controlar certos alunos devido ao grau de agitação deles.

Outro aspecto é de que o tempo de espera entre o almoço, o início de uma oficina no meio-dia ou até mesmos as atividades TAP tinham como espaço-tempo de transição o pátio da escola. Isso quer dizer que entre a passagem de um tempo e outro, os alunos ficavam brincando de "pega-pega", correndo e sendo cuidados pelos animadores. Portanto, não havia um tempo de pausa no qual as crianças pudessem descansar antes de começarem a aula regular do turno da tarde. A gama de propostas do tempo do meio dia e do fim da tarde fazem da EFr uma escola 
que funciona, em média, 9h15 min. por dia. Ela é, portanto, um espaço que possibilita a realização de diversas atividades diferenciadas para crianças cujas famílias têm renda.

Não obstante, tal realidade difere para os alunos que não possuem renda. A oferta de um tempo de atividade paga limita a participação das crianças. Paradoxalmente, pode-se dizer, essas atividades foram pensadas para promover a integração cultural e social das crianças oriundas das camadas mais populares.

A temática da mistura social ${ }^{6}$, bastante discutida na sociologia educacional francesa, ganha destaque não somente pelo fato de debater-se a falta de interação entre as crianças de periferia e de outros bairros como, também, pelo fato de que o Estado ao concentrar todas as atividades dentro de um único espaço, limita o poder de mobilidade espacial das crianças na escola e acaba, também, ofuscando os lugares que as mesmas ocupam na sociedade.

A divisão de tempo de atividades propunha subjetivamente a existência de uma linha divisória que separa a escola formal da escola do lazer: de um lado se tem as atividades lúdicas: jogar, dançar, correr, brigar, criar e de outro, os conhecimentos formais da escola tradicional anunciados no capítulo anterior. Logo, a falta de diálogo entre ambos os espaços, os muros que os separam, de certa forma, reforçavam as metodologias empregadas pelos educadores e professores: de um lado aprendemos, de outro brincamos e jogamos.

\section{QUEM ESCONDEU O RITMO OCULTO? CONSIDERAÇÕES FINAIS}

A partir de uma metodologia comparativa, objetivou-se analisar como os Ritmos Escolares, no Brasil e na França, se manifestam nos cotidianos escolares, considerando o exemplo de duas escolas públicas de periferia, uma em cada país.

O que se pretendia não era apontar os aspectos considerados "positivos" que trazem consigo o aumento da carga horária escolar e a diferenciação das atividades e atores. Ao contrário, o que se pretendia era apontar os pontos frágeis deste duplo espaço educativo e, também, defender a hipótese de que mesmo quando o debate é sobre o de tempo de escola o que, paradoxalmente, parece não mudar com o tempo é a concepção tradicional sobre o que é, o que se faz e como se faz a escola.

Tempo de escola, tempo de atividades extraescolares, périsciolaires, tempo de mais educação, de menos educação são sinônimos que traduzem a constatação de que é preciso (re) pensar o tempo que se passa e, porque não dizer, que se vive na/a escola. 
Os exemplos observados mostraram que há questões pontuais e práticas que ainda precisam ser pensadas. Primeiro, trata-se de financiamento. Não se pode pensar em aperfeiçoar os tempos escolares se não houver investimentos massivos neles, se não se contratar pessoal qualificado para o aumento de tempo, se não existir uma transformação estrutural do espaço da escola, se não se transcender os muros da escola. Se não houver formação para os monitores em responsabilidade do extraescolar.

Do lado das regentes, se a forma de "dar aula" continuar sendo fundada na ideia de que o aluno é o único responsável pelo seu fracasso ou sucesso. Na ideia de que a função do professor é transmitir conteúdos e o aluno absorver, de nada serve propor o alargamento do tempo de escola.

De um ponto de vista teórico, pode-se afirmar que os Ritmos Escolares se manifestam, tanto na organização formal do tempo de escola, como, também, por meio de ideologias, paradigmas, formas de pensar e ser. Concluímos, portanto, que o Ritmo escolar, como concepção teórica, está carregado de sentidos, história de crenças e de relações de poder que se manifestam, tanto nas práticas escolares dos professores em sala de aula quanto na própria história de implementação e das intencionalidades subjacentes. Tais manifestações são forças motoras que fizeram e fazem com que o tempo que a criança passa na escola permaneça como um elemento fundamental de discussão no campo da educação.

\section{REFERÊNCIAS}

APPLE, Michael. Ideologia e currículo. São Paulo: Editora Brasiliense, 1982.

BOURDIEU, Pierre; PASSERON, Jean-Claude. A reprodução. Elementos para uma teoria do sistema de ensino. 3. ed. Rio de Janeiro: Editora Francisco Alves, 1970.

BRASIL. Lei $\mathbf{n}^{\circ}$ 9.394, de 20 de setembro de 1996. Estabelece as diretrizes e bases da educação nacional. Brasília: 20 set. 1996. Disponível em:

http://www.planalto.gov.br/ccivil_03/leis/L9394.htm. Acesso em: 14 fev. 2017.

BRASIL. Novo Mais Educação. Brasília, 2017a. Disponível em:

https://novomaiseducacao.caeddigital.net/\#!/home . Acesso em: 27 set. 2017.

BRASIL. Programa Novo Mais Educação/PNME. Perguntas frequentes - execução e monitoramento. Brasília: 2017b. Disponível em:

http://portal.mec.gov.br/index.php?option $=$ com_docman\&view $=$ download\&alias $=66561$ perguntas-frequentes-monitoramento-maiseducacao-pdf\&category_slug=junho-2017pdf\&Itemid=30192 . Acesso em: 29 set. 2017. 
CHARLOT, Bernard. Relação com a escolar e o saber em bairros populares. Perspectiva. Florianópolis, v. 12, n. Especial, p.17-32, 2002. Disponível em: https://periodicos.ufsc.br/index.php/perspectiva/article/view/10237/9476. Acesso em: 29 jan. 2017.

FRANÇA. Le Bulletin officiel, n.23 du 29 juin 2017. Dérogations à l'organisation de la semaine scolaire. Paris, 23 e 29 jun. 2017. 2017. Disponível em: http://www.education.gouv.fr/pid285/bulletin_officiel.html?cid_bo=118204. Acesso em: 18 sep. 2017.

MERLE, Pierre. La carte scolaire et son assouplissement. Politique de mixité sociale ou de ghettoïsation des établissements? Presses Universitaires de France, Paris, v.2, n.1, p.37-50, 2011.

GONCALVES, Maria Fernanda. Currículo Oculto e Culturas de aprendizagem na formação de professores. Porto Alegre: Artmed, 1994.

LOPES, Alice C.; MACEDO, Elisabeth. Teorias de currículo. São Paulo: Cortez, 2011.

MOREIRA, Antônio F.; SILVA, Tomaz T. Currículo, Cultura e Sociedade. 2 ed. São Paulo: Editora Cortez, 1995.

PALAMIDESSI, Mariano. Tempo e currículo: o quadro de horário e a distribuição escolar das ocupações In: LOPES, Alice C.; MACEDO, Elizabeth. Currículo: debates contemporâneos. São Paulo: Cortez Editora, 2002. p. 115-132.

PERRENOUD, Philippe. Métier d'élève et sens du travail scolaire. 8. ed. Issy-lesMoulineaux : ESF Editeur, 2013.

SILVA, Tomaz T. Documentos de identidade. Uma introdução às teorias do currículo. 2. ed. Belo Horizonte: Autêntica, 2005.

VIGOUR, Cécile. La Comparaison em sciences sociales. Pratiques et méthodes. : Paris: La Découverte, 2005.

\section{NOTAS}

${ }^{1}$ O título deste trabalho foi inspirado na obra de Tomáz Tadeu da Silva, "Documentos de identidade: uma introdução às teorias do currículo" " a pesquisa foi realizada no nível de Mestrado em Educação e almejou se inscrever num campo investigativo crítico do currículo escolar.

${ }^{2}$ As anotações aqui apresentadas fazem parte de nosso Diário de Bordo.

${ }^{3}$ O Novo Mais Educação surgiu no ano de 2015 após o golpe presidencial de 2015 que destituiu a presidente Dilma Rousseff. Anterior a este, se desenvolvia desde 2007 o programa Mais Educação. A aplicação do Novo Mais Educação tirou de funcionamento o antigo reformulando algumas concepções de base da proposta inicial: diminuição do investimento nas atividades culturais e foco no reforço escolar. 


\begin{abstract}
${ }^{4}$ A entrevista foi realizada com a Mediadora Carla no fim do mês de junho, mas as atividades no Programa começaram no fim do mês de março, logo os alunos ficaram cerca de três meses sem merenda. A entrevista com o coordenador Lucas ocorreu dois meses após as observações, no dia 17 de agosto. Nessa data, a merenda já estava sendo distribuída e as crianças que frequentavam o Programa pela manhã já estavam almoçando. Sobre o atraso, disseram que houve problemas com a liberação da verba na prefeitura da cidade.

${ }^{6}$ Merle (2011) relata que os estudos sobre este aspecto na educação montam de uma literatura anglo-saxônica dita como scholl mix effect. De forma resumida, quer dizer que em uma escola possui um concentrado número de estudantes desfavorecidos socialmente e culturalmente do capital cultural que domina a escola, sobretudo, nas camadas mais populares o nível de sucesso escolar é baixo ao passo que numa situação contrária, nos bairros mais abastados, o processo é inverso. Assim, a mistura social, quer dizer a mescla de diferentes culturas sociais, capitais culturais, ainda que seja um debate bastante tencionado e que mereça ser aprofundado, pode ser uma proposta de coesão e igualdade social importante em matéria de educação.
\end{abstract}

\title{
Recebido em: 06/02/2018
}

Aprovado em: 20/07/2020 